\begin{tabular}{lcccr} 
T H E & A R C H I V E & O F & M E C H A N I C A L & E N G I N E E R I N G \\
\hline VOL. LIX & 2012 & Number 4
\end{tabular}

10.2478/v10180-012-0022-1

Key words: Buckling, cylindrical shell, composite, carbon nanotubes, Rayleigh-Ritz method

JAFAR ESKANDARI JAM*, ESMAIL ASADI*

\title{
BUCKLING ANALYSIS OF COMPOSITE CYLINDRICAL SHELLS REINFORCED BY CARBON NANOTUBES
}

\begin{abstract}
In this paper, the authors investigate a cylindrical shell reinforced by carbon nanotubes. The critical buckling load is calculated using analytical method when it is subjected to compressive axial load. The Mori-Tanaka method is firstly utilized to estimate the effective elastic modulus of composites having aligned oriented straight CNTs. The eigenvalues of the problem are obtained by means of an analytical approach based on the optimized Rayleigh-Ritz method. There is presented a study on the effects of CNTs volume fraction, thickness and aspect ratio of the shell, CNTs orientation angle, and the type of supports on the buckling load of cylindrical shells. Furthermore the effect of CNTs agglomeration is investigated when CNTs are dispersed none uniformly in the polymer matrix. It is shown that when the CNTs are arranged in $90^{\circ}$ direction, the highest critical buckling load appears. Also, the results are plotted for different longitudinal and circumferential mode numbers. There is a specific value for aspect ratio of the cylinder that minimizes the buckling load. The results reveal that for very low CNTs volume fractions, the volume fraction of inclusions has no important effect on the critical buckling load.
\end{abstract}

\section{Nomenclature}

$E_{m}, v_{m}$

$$
r, \theta, z
$$

$\sigma_{r r}, \sigma_{\theta \theta}, \sigma_{z z}, \sigma_{\theta z}, \sigma_{r z}, \sigma_{r \theta}$

$\varepsilon_{r r}, \varepsilon_{\theta \theta}, \varepsilon_{z z}, \gamma_{\theta z}, \gamma_{r z}, \gamma_{r \theta}$

$Q_{r r}, Q_{r \theta}, Q_{r z}, Q_{\theta \theta}, Q_{\theta z}, Q_{z z}$

$G_{\theta z}, G_{r z}, G_{r \theta}$

$c_{m}, c_{r}$

$k_{r}, l_{r}, m_{r}, n_{r}, p_{r}$

$\left[Q_{i j}\right],\left[\bar{Q}_{i j}\right]$
Young's modulus and Poisson's ratio of matrix

cylindrical principal directions

stress components

strain components

stiffness coefficients

volume fractions of matrix and CNTs respectively

Hill's elastic modulus for CNTs

stiffness matrix and reduced transformed stiffness matrix

* Composite Materials and Technology Center, Tehran, Iran; E-mail: jejam@mail.com 


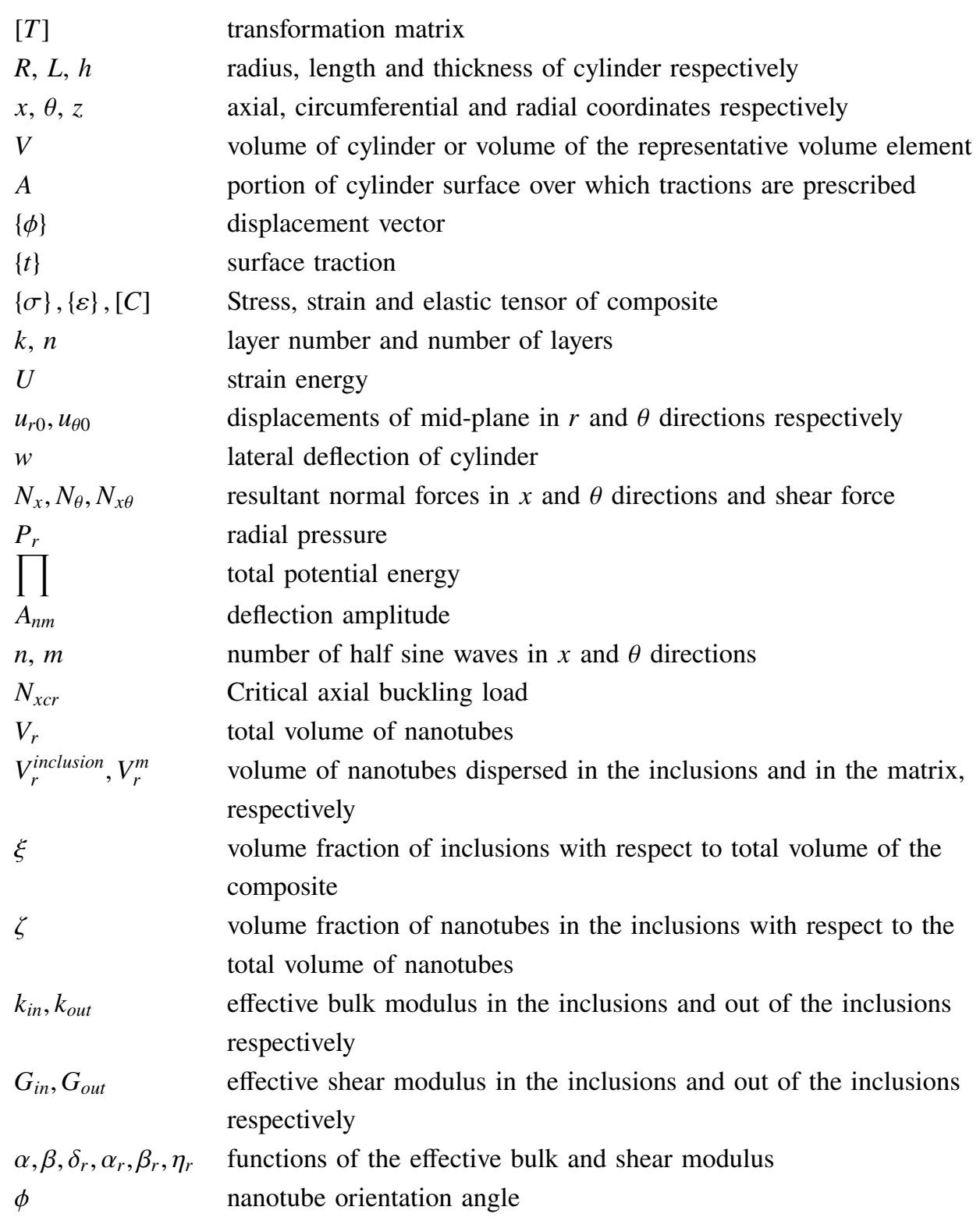

\section{Introduction}

Composites of carbon nanotubes (CNTs) dispersed in metallic or polymeric matrices have attracted a considerable attention in recent years [1]. CNTs with their superior stiffness and strength have been regarded as an excellent candidate for reinforcing part in advanced composites with high strength and low density characteristics. A number of experimental and theoretical studies have shown that CNTs have excellent mechanical properties, 
such as high strength and stiffness to weight ratios, very high aspect ratio (ratio of length to diameter of CNTs), and enormous electrical and thermal conductivities [2-4]. Therefore, the presence of the nanotubes can improve the strength and stiffness of polymers as well as electrical and thermal conductivities of polymer-based composite structures [5-9].

The buckling load of a composite cylindrical shell depends on a variety of parameters, such as the geometry of the cylinder, properties of reinforcement, and boundary conditions. Hilburger et al [10] presented buckling results from a numerical study of the response of thin-walled compression-loaded quasi isotropic laminated composite cylindrical shells with unreinforced and reinforced square cutouts. Dong and Mistry [11] carried out an experimental investigation into the buckling failure of filament wound glass reinforced plastic cylinders subjected to a combination of external pressure and axial compression. An analytical and experimental study of the buckling behavior of thin-walled carbon fiber reinforced polymer (CFRP) laminated shells under combined axial and torsion loading is done by Meyer-Piening et al. [12]. Elghazouli et al. [13] present the results of buckling tests on laminated composite cylinders made of glass fiber reinforced plastic (GFRP). The results of this experimental study demonstrate the influence of laminate orientation on the buckling strength of composite cylinders under axial compression. Same authors [14] studied a numerical simulation for the buckling behaviour of laminated glass-reinforced plastic cylinders under axial compression. Topal [15] studied multi objective optimization of laminated cylindrical shells to maximize a weighted sum of the frequency and buckling load under external load. He used the first order shear deformation theory for the finite element formulation of the laminated shells. Chryssanthopoulos et al. [16] give a detailed research on the numerical finite element validation for laminated GFRP cylinders subjected to concentric and eccentric compression. Both linear eigenvalue analysis and geometrically nonlinear simulations are undertaken using a general purpose finite element program.

The Effects of CNTs volume fraction, CNTs orientation angles, and agglomeration of CNTs are important for studying the buckling of structures. Jam and Maghamikia [17] derived the buckling equations of laminated rectangular plates using classical plate theory. Also the critical compressive load in the buckling of circular and annular composite plates reinforced with carbon nanotubes (CNTs) is calculated using finite element method by same authors [18]. The developed model is based on the third-order shear deformation theory for moderately thick laminated plates, and the effects of CNTs orientation angles and thickness-to-inner radius ratio on the buckling of composite plates are discussed. Jam et al. [19] obtained the buckling analysis of circular annular plate reinforced by CNTs subjected to compres- 
sive and torsional loads with various axially symmetric boundary conditions. The results illustrate that the critical buckling load decreases as a result of non uniform dispersion of CNTs in the polymer matrix.

In this paper, the critical buckling load of a composite cylindrical shell reinforced by CNTs is obtained by means of analytical approach based on optimized Rayleigh-Ritz method when the composite cylinder is under axial load. Also, the Effects of CNTs volume fraction, thickness and aspect ratio of shell, CNTs orientation angles, and agglomeration of CNTs with different types of boundary supports are studied on the buckling load of cylindrical shells.

\section{Effective modulus of the composite}

In this section, the effective modulus of the composite cylinder reinforced by CNTs is developed. Different methods are available to estimate the overall properties of the composite [20]. Due to its simplicity and accuracy, even at high volume fractions of the inclusions, the Mori-Tanaka method [21] is employed here. Also, CNTs are assumed to be aligned and straight with the uniform dispersion in the polymer. The matrix is assumed to be elastic and isotropic, with the Young's modulus $E_{m}$ and the Poisson's ratio $v_{m}$.

The constitutive relations for a layer of the composite with the principal axes parallel to the $r, \theta$ and $z$ directions are [22]:

$$
\left[\begin{array}{c}
\sigma_{r r} \\
\sigma_{\theta \theta} \\
\sigma_{z z} \\
\sigma_{\theta z} \\
\sigma_{r z} \\
\sigma_{r \theta}
\end{array}\right]=\left[\begin{array}{cccccc}
Q_{r r} & Q_{r \theta} & Q_{r z} & 0 & 0 & 0 \\
Q_{r \theta} & Q_{\theta \theta} & Q_{\theta z} & 0 & 0 & 0 \\
Q_{r z} & Q_{\theta z} & Q_{z z} & 0 & 0 & 0 \\
0 & 0 & 0 & G_{\theta z} & 0 & 0 \\
0 & 0 & 0 & 0 & G_{r z} & 0 \\
0 & 0 & 0 & 0 & 0 & G_{r \theta}
\end{array}\right]\left\{\begin{array}{c}
\varepsilon_{r r} \\
\varepsilon_{\theta \theta} \\
\varepsilon_{z z} \\
\gamma_{\theta z} \\
\gamma_{r z} \\
\gamma_{r \theta}
\end{array}\right\}
$$

where $\sigma_{i j}, \varepsilon_{i j}$ and $Q_{i j}$ are the stress components, the strain components and the stiffness coefficients respectively. According to the Mori-Tanaka method, the stiffness coefficients are given by [23]: 


$$
\begin{aligned}
Q_{\theta \theta}= & \frac{E_{m}\left\{E_{m} c_{m}+2 k_{r}\left(1+v_{m}\right)\left[1+c_{r}\left(1-2 v_{m}\right)\right]\right\}}{2\left(1+v_{m}\right)\left[E_{m}\left(1+c_{r}-2 v_{m}\right)+2 c_{m} k_{r}\left(1-v_{m}-2 v_{m}^{2}\right)\right]}+ \\
& \frac{E_{m}\left[E_{m} c_{m}+2 m_{r}\left(3+c_{r}-4 v_{m}\right)\left(1+v_{m}\right)\right]}{2\left(1+v_{m}\right)\left\{E_{m}\left[c_{m}+4 c_{r}\left(1-v_{m}\right)\right]+2 m_{r} c_{m}\left(3+c_{r}-4 v_{m}^{2}\right)\right\}} \\
Q_{r \theta}= & Q_{r z}=\frac{E_{m}\left\{c_{m} v_{m}\left[E_{m}+2 k_{r}(1+v)\right]+2 c_{r} l_{r}\left(1-v_{m}^{2}\right)\right\}}{\left(1+v_{m}\right)\left[2 c_{m} k_{r}\left(1-v_{m}-2 v_{m}^{2}\right)+E_{m}\left(1+c_{r}-2 v_{m}\right)\right]} \\
Q_{z z}= & \frac{E_{m}\left\{c_{m} v_{m}\left[E_{m}+2 k_{r}(1+v)\right]+2 c_{r} l_{r}\left(1-v_{m}^{2}\right)\right\}}{\left(1+v_{m}\right)\left[2 c_{m} k_{r}\left(1-v_{m}-2 v_{m}^{2}\right)+E_{m}\left(1+c_{r}-2 v_{m}\right)\right]} \\
G_{r \theta}= & \frac{E_{m}\left[E_{m} c_{m}+2 m_{r}\left(3+c_{r}-4 v_{m}\right)\left(1+v_{m}\right)\right]}{2\left(1+v_{m}\right)\left\{E_{m}\left[c_{m}+4 c_{r}\left(1-v_{m}\right)\right]+2 m_{r} c_{m}\left(3+c_{r}-4 v_{m}^{2}\right)\right\}} \\
G_{r z}= & G_{z \theta}=\frac{E_{m}\left[E_{m} c_{m}+2\left(1+c_{r}\right) p_{r}\left(1+v_{m}\right)\right]}{2\left(1+v_{m}\right)\left[E_{m}\left(1+c_{r}\right)+2 c_{m} p_{r}\left(1+v_{m}\right)\right]}
\end{aligned}
$$

where $c_{m}$ and $c_{r}$ are the volume fractions of the matrix and the CNTs, respectively, and $k_{r}, l_{r}, m_{r}, n_{r}$ and $p_{r}$ are the Hill's elastic modulus for the CNTs [24]. $k_{r}$ is the plane-strain bulk modulus normal to the CNT direction, $n_{r}$ is the uniaxial tension modulus in the CNT direction, $l_{r}$ is the associated cross modulus, $m_{r}$ and $p_{r}$ are the shear moduli in planes normal and parallel to the CNT direction, respectively.

The reduced transformed stiffness matrix is [22]:

$$
\left[\bar{Q}_{i j}\right]=[T]\left[Q_{i j}\right][T]^{-1}
$$

where $[T]$ is the transformation matrix which is given by [21]:

$$
[T]=\left[\begin{array}{cccccc}
\cos ^{2} \theta & \sin ^{2} \theta & 0 & 0 & 0 & -\sin 2 \theta \\
\sin ^{2} \theta & \cos ^{2} \theta & 0 & 0 & 0 & \sin 2 \theta \\
0 & 0 & 1 & 0 & 0 & 0 \\
0 & 0 & 0 & \cos \theta & \sin \theta & 0 \\
0 & 0 & 0 & -\sin \theta & \cos \theta & 0 \\
\sin \theta \cos \theta & -\sin \theta \cos \theta & 0 & 0 & 0 & \cos ^{2} \theta-\sin ^{2} \theta
\end{array}\right]
$$

\section{Analytical solution}

The CLPT is used to work the analytical solution out, as it is simply used for a moderate thick isotropic plates and shells. According to Fig. $1, R$ and $L$ 
are respectively the radius and length of cylinder, and $h$ denotes the thickness of it. The boundary condition on edges can be simply supported or clamped and the cylinder is under axial loading. In Fig. 1, the axial coordinate is $x$, the circumferential coordinate is $\theta$, and the thickness coordinate normal to the shell surface is $z$.

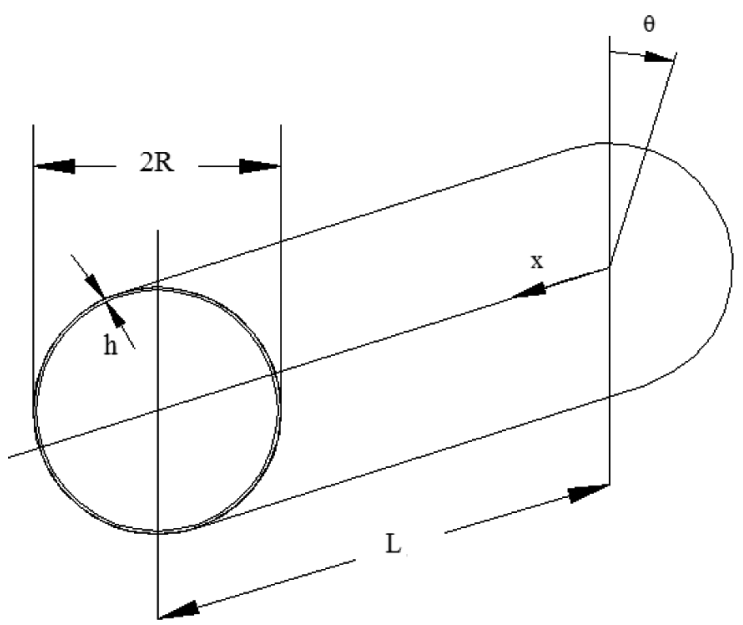

Fig. 1. Geometry of cylindrical shell and the assumed coordinate system

\subsection{Total potential energy}

Total potential energy of the cylinder, due to the internal strain and the surface traction, is given by [25]:

$$
\Pi=\int_{V}\{\varepsilon\}^{T}\{\sigma\} d V+\int_{A}\{\phi\}^{T}\{t\} d A
$$

The first term in Eq. (5) is the strain energy in which $V$ denotes the volume of the cylinder. The second term is the energy produced by surface traction and $A$ is the portion of cylinder surface over which tractions are prescribed. $\{\phi\}$ is the displacement vector and $\{t\}$ is the surface traction. The constitutive equation relating stress and strain can be written as:

$$
\{\sigma\}=[C]\{\varepsilon\}
$$

where $[C]$ is the elastic tensor whose components are given by [22]:

$$
\begin{aligned}
& C_{11}=\sum_{k=1}^{n}\left[\bar{Q}_{r r}\right]_{k} \quad C_{22}=\sum_{k=1}^{n}\left[\bar{Q}_{\theta \theta}\right]_{k} \quad C_{12}=\sum_{k=1}^{n}\left[\bar{Q}_{r \theta}\right]_{k} \\
& C_{66}=\sum_{k=1}^{n}\left[\bar{Q}_{z z}\right]_{k} \quad C_{16}=\sum_{k=1}^{n}\left[\bar{Q}_{r z}\right]_{k} \quad C_{26}=\sum_{k=1}^{n}\left[\bar{Q}_{z \theta}\right]_{k}
\end{aligned}
$$


where $k$ denotes the layer number and $n$ is the number of layers. According to Eqs (6) and (7), the strain energy can be written as:

$$
U=\frac{1}{2} \int_{V}\left[\begin{array}{lll}
\varepsilon_{r} & \varepsilon_{\theta} & \gamma_{r \theta}
\end{array}\right]\left[\begin{array}{lll}
\bar{Q}_{r r} & \bar{Q}_{r \theta} & \bar{Q}_{r z} \\
\bar{Q}_{r \theta} & \bar{Q}_{\theta \theta} & \bar{Q}_{z \theta} \\
\bar{Q}_{r z} & \bar{Q}_{z \theta} & \bar{Q}_{z z}
\end{array}\right]\left[\begin{array}{c}
\varepsilon_{r} \\
\varepsilon_{\theta} \\
\gamma_{r \theta}
\end{array}\right] d V
$$

The relations between the strain and the displacement for the CLPT are given by [25]:

$$
\begin{gathered}
\varepsilon_{r}=\frac{\partial u_{r}}{\partial r}=\frac{\partial u_{r 0}}{\partial r}-z \frac{\partial^{2} w}{\partial r^{2}} \\
\varepsilon_{\theta}=\frac{1}{r} \frac{\partial u_{\theta}}{\partial \theta}+\frac{u_{r}}{r}=\frac{1}{r} \frac{\partial u_{r 0}}{\partial \theta}+\frac{u_{r 0}}{r}-\frac{z}{r^{2}} \frac{\partial^{2} w}{\partial \theta^{2}}-\frac{z}{r} \frac{\partial w}{\partial r} \\
\varepsilon_{r \theta}=\frac{1}{2}\left(\frac{1}{r} \frac{\partial u_{r 0}}{\partial \theta}-\frac{\partial u_{\theta 0}}{\partial r}-\frac{u_{\theta 0}}{r}\right)-\frac{2 z}{r} \frac{\partial^{2} w}{\partial r \partial \theta}+\frac{2 z}{r^{2}} \frac{\partial w}{\partial \theta}
\end{gathered}
$$

where $u_{r 0}$ and $u_{\theta 0}$ are the displacements of the mid-plane in $r$ and $\theta$ directions, respectively, which are assumed to be zero because there is no coupling between the in-plane and the out-of-plane displacements. $w(r, \theta)$ indicates the displacement in $z$ direction or the lateral deflection of the composite cylinder. Substituting Eq. (9) into Eq. (8) for the defined coordinate system mentioned in Fig. 1 yields:

$$
\begin{gathered}
U=\frac{1}{2} \int_{V}\left[\begin{array}{ccc}
-z \frac{\partial^{2} w}{\partial x^{2}} & \frac{w}{R}-z \frac{\partial^{2} w}{\partial \theta^{2}} & \frac{1}{2}\left(\frac{z}{R}+1\right) \frac{\partial^{2} w}{\partial x \partial \theta}
\end{array}\right] \\
{\left[\begin{array}{ccc}
\overline{C_{11}} & \overline{C_{12}} & 0 \\
\overline{C_{21}} & \overline{C_{22}} & 0 \\
0 & 0 & \overline{C_{66}}
\end{array}\right]\left[\begin{array}{c}
-z \frac{\partial^{2} w}{\partial x^{2}} \\
\frac{w}{R}-z \frac{\partial^{2} w}{\partial \theta^{2}} \\
\frac{1}{2}\left(\frac{z}{R}+1\right) \frac{\partial^{2} w}{\partial x \partial \theta}
\end{array}\right] d V}
\end{gathered}
$$

The surface traction is given by [26]:

$$
\begin{aligned}
& \int_{S r}^{T_{i} u_{i} d S=\int_{0}^{2 \pi} \int_{0}^{L}\left(P_{r} w\right) R d x d \theta}-\int_{0}^{2 \pi R} \int_{0}^{L}\left\{N_{x}\left[\frac{\partial u_{0}}{\partial x}+\frac{1}{2}\left(\frac{\partial w}{\partial x}\right)^{2}\right]\right. \\
& \left.+N_{\theta}\left[\frac{1}{R} \frac{\partial v_{0}}{\partial \theta}+\frac{w}{R}+\frac{1}{2}\left(\frac{1}{R} \frac{\partial w}{\partial \theta}\right)^{2}\right]+N_{x \theta}\left[\frac{1}{R} \frac{\partial u_{0}}{\partial \theta}+\frac{\partial v_{0}}{\partial x}+2\left(\frac{1}{R} \frac{\partial w}{\partial \theta}\right)\left(\frac{\partial w}{\partial x}\right)\right]\right\} R d x d \theta
\end{aligned}
$$


where, $N_{x}$ is the resultant force in the $x$ direction and $N_{x \theta}, N_{\theta}$ and $P_{r}$ are assumed to be zero. Eqs (10) and (11) are substituted into Eq. (5). Under axial compression, the total potential energy is simplified to:

$$
\begin{aligned}
& \prod=\frac{1}{2} \int_{R}^{R+h} \int_{0}^{2 \pi} \int_{0}^{L}\left[\overline{C_{11}} z^{2}\left(\frac{\partial^{2} w}{\partial x^{2}}\right)^{2}-2 \overline{C_{12}} z \frac{w}{R} \frac{\partial^{2} w}{\partial x^{2}}+2 \overline{C_{12}} z^{2}\left(\frac{\partial^{2} w}{\partial x^{2}}\right)\left(\frac{\partial^{2} w}{\partial \theta^{2}}\right)\right. \\
& \left.+\overline{C_{22}}\left(\frac{w}{R}\right)^{2}-2 \overline{C_{22} z}\left(\frac{w}{R}\right)\left(\frac{\partial^{2} w}{\partial \theta^{2}}\right)^{2}+\overline{C_{22}} z^{2}\left(\frac{\partial^{2} w}{\partial \theta^{2}}\right)^{2}+\frac{1}{4} \overline{C_{66}}\left(\frac{\partial^{2} w}{\partial x \partial \theta}\right)^{2}\right] d z d \theta d x \\
& -\int_{0}^{2 \pi R} \int_{0}^{L} N_{x}\left[\frac{\partial u_{0}}{\partial x}+\frac{1}{2}\left(\frac{\partial w}{\partial x}\right)^{2}\right] R d x d \theta
\end{aligned}
$$

Based on the levy solution [25], it is important to find a suitable function for the lateral deflection. It is assumed that the lateral deflection is a separate solution of $x$ and $\theta$ variables:

$$
w(x, \theta)=f(x) g(\theta)
$$

For the simply supported boundary conditions at the ends of the cylinder (S-S), the lateral deflection is defined as [27]:

$$
w=\sum_{m=1}^{\infty} \sum_{n=1}^{\infty} A_{m n} \sin \left(\alpha_{m} x\right) \cos (n \theta), \quad \alpha_{m}=\frac{m \pi}{L}
$$

where $A_{n m}$ is the deflection amplitude, $n$ and $m$ are the number of half sine waves in the $x$ and $\theta$ directions. So, Eq. (14) is satisfied with two conditions at the ends of the composite cylinder:

$$
\begin{array}{ll}
w=0 & \text { at } x=0, L \\
\frac{\partial^{2} w}{\partial x^{2}}=0 & \text { at } x=0, L
\end{array}
$$


Substituting the solution $w(x, \theta)$ from Eq. (14) into Eq. (12) results in:

$$
\begin{aligned}
& \prod=\frac{1}{2} \int_{R}^{R+h} \int_{0}^{2 \pi} \int_{0}^{L}\left\{z^{2}\left(\alpha_{m}\right)^{4}\left(\bar{C}_{11}\right) \sum_{m=1}^{\infty} \sum_{n=1}^{\infty}\left(A_{m n} \sin \alpha_{m} x \cos n \theta\right)^{2}\right. \\
& +\frac{2}{R} z\left(\alpha_{m}\right)^{2}\left(\bar{C}_{12}\right) \sum_{m=1}^{\infty} \sum_{n=1}^{\infty}\left(A_{m n} \sin \alpha_{m} x \cos n \theta\right)^{2}+\frac{1}{R^{2}}\left(\bar{C}_{22}\right) \sum_{m=1}^{\infty} \sum_{n=1}^{\infty}\left(A_{m n} \sin \alpha_{m} x \cos n \theta\right)^{2} \\
& +z^{2} n^{4}\left(\bar{C}_{22}\right) \sum_{m=1}^{\infty} \sum_{n=1}^{\infty}\left(A_{m n} \sin \alpha_{m} x \cos n \theta\right)^{2}+\frac{1}{4}\left(n \alpha_{m}\right)^{2}\left(\bar{C}_{66}\right) \sum_{m=1}^{\infty} \sum_{n=1}^{\infty}\left(A_{m n} \cos \alpha_{m} x \sin n \theta\right)^{2} \\
& +2 \bar{C}_{12} z^{2}\left(n \alpha_{m}\right)^{2} \sum_{m=1}^{\infty} \sum_{n=1}^{\infty}\left(A_{m n} \sin \alpha_{m} x \cos n \theta\right)^{2} \\
& \left.-\frac{2}{R} \bar{C}_{22} z n^{4} \sum_{m=1}^{\infty} \sum_{n=1}^{\infty}\left(A_{m n} \sin \alpha_{m} x \cos n \theta\right)^{2}\right\} R d x d \theta d z \\
& -\int_{0}^{2 \pi} \int_{0}^{L}\left\{N_{x}\left[\frac{1}{2}\left(\alpha_{m}\right)^{4} \sum_{m=1}^{\infty} \sum_{n=1}^{\infty}\left(A_{m n} \sin \alpha_{m} x \cos n \theta\right)^{2}\right] R d x d \theta\right.
\end{aligned}
$$

By the conversion of the triple integral into the double one, Eq. (16) is simplified to Eq. (17):

$$
\begin{aligned}
& \prod=\frac{1}{2} \int_{0}^{2 \pi} \int_{0}^{L}\left\{\frac{1}{3}\left((R+h)^{3}-R^{3}\right)\left(\alpha_{m}\right)^{4}\left(\bar{C}_{11}\right) \sum_{m=1}^{\infty} \sum_{n=1}^{\infty}\left(A_{m n} \sin \alpha_{m} x \cos n \theta\right)^{2}\right. \\
& +\frac{1}{R}\left((R+h)^{2}-R^{2}\right)\left(\alpha_{m}\right)^{2}\left(\bar{C}_{12}\right) \sum_{m=1}^{\infty} \sum_{n=1}^{\infty}\left(A_{m n} \sin \alpha_{m} x \cos n \theta\right)^{2} \\
& +\frac{h}{R^{2}}\left(\bar{C}_{22}\right) \sum_{m=1}^{\infty} \sum_{n=1}^{\infty}\left(A_{m n} \sin \alpha_{m} x \cos n \theta\right)^{2} \\
& +\frac{1}{3}\left((R+h)^{3}-R^{3}\right) n^{4}\left(\bar{C}_{22}\right) \sum_{m=1}^{\infty} \sum_{n=1}^{\infty}\left(A_{m n} \sin \alpha_{m} x \cos n \theta\right)^{2} \\
& +\frac{h}{4}\left(n \alpha_{m}\right)^{2}\left(\bar{C}_{66}\right) \sum_{m=1}^{\infty} \sum_{n=1}^{\infty}\left(A_{m n} \cos \alpha_{m} x \sin n \theta\right)^{2} \\
& +\frac{2}{3} \bar{C}_{12}\left((R+h)^{3}-R^{3}\right)\left(n \alpha_{m}\right)^{2} \sum_{m=1}^{\infty} \sum_{n=1}^{\infty}\left(A_{m n} \sin \alpha_{m} x \cos n \theta\right)^{2} \\
& -\frac{1}{R} \bar{C}_{22}\left((R+h)^{2}-R^{2}\right) n^{4} \sum_{m=1}^{\infty} \sum_{n=1}^{\infty}\left(A_{m n} \sin \alpha_{m} x \cos n \theta\right)^{2} \\
& \left.-N_{x}\left[\left(\alpha_{m}\right)^{4} \sum_{m=1}^{\infty} \sum_{n=1}^{\infty}\left(A_{m n} \sin \alpha_{m} x \cos n \theta\right)^{2}\right]\right\} R d x d \theta
\end{aligned}
$$

By substituting the values of sine and cosine functions in Eq. (17) one can see that the total energy $\Pi$ is a function of $A_{m n}$. Moreover, for the cylinder to be in equilibrium, $\Pi$ must be stationary with respect to $A_{m n}$. So:

$$
\frac{\partial \Pi}{\partial A_{m n}}=0
$$


The buckling load $N_{c r}$ is obtained by solving Eq. (18) as follows:

$$
\begin{aligned}
& N_{c r}=\left(\frac{2}{\pi L \alpha_{m}^{4}}\right)\left\{\frac{1}{3}\left((R+h)^{3}-R^{3}\right)\left(\alpha_{m}\right)^{4}\left(\frac{\pi L}{2}\right)\left(\bar{C}_{11}\right)+\left(\frac{(R+h)^{2}-R^{2}}{R}\right)\left(\alpha_{m}\right)^{2}\left(\frac{\pi L}{2}\right)\left(\bar{C}_{12}\right)\right. \\
& +\frac{h}{R^{2}}\left(\frac{\pi L}{2}\right)\left(\bar{C}_{22}\right)+\frac{1}{3}\left((R+h)^{3}-R^{3}\right) n^{4}\left(\frac{\pi L}{2}\right)\left(\bar{C}_{22}\right)+\frac{h}{4}\left(n \alpha_{m}\right)^{2}\left(\frac{\pi L}{2}\right)\left(\bar{C}_{66}\right) \\
& \left.+\frac{2}{3}\left(\frac{\pi L}{2}\right) \bar{C}_{12}\left((R+h)^{3}-R^{3}\right)\left(n \alpha_{m}\right)^{2}-\frac{1}{R} \bar{C}_{22}\left(\frac{\pi L}{2}\right)\left((R+h)^{2}-R^{2}\right) n^{4}\right\}
\end{aligned}
$$

Also for the clamped boundary conditions $(\mathrm{C}-\mathrm{C})$ at the ends of the cylinder, the lateral deflection is defined as [27]:

$$
w=\sum_{m=1}^{\infty} \sum_{n=1}^{\infty} A_{m n}\left(1-\cos \left(\alpha_{m} x\right)\right) \cos (n \theta)
$$

So, Eq. (20) is satisfied with two conditions at ends of the composite cylinder:

$$
\begin{array}{ll}
w=0 & \text { at } x=0, L \\
\frac{\partial w}{\partial x}=0 & \text { at } x=0, L
\end{array}
$$

Substituting the solution $w(x, y)$ from Eq. (20) into Eq. (21) results in:

$$
\begin{aligned}
& \prod=\frac{1}{2} \int_{R}^{R+h} \int_{0}^{2 \pi} \int_{0}^{L}\left\{z^{2}\left(\alpha_{m} x\right)^{4}\left(\bar{C}_{11}\right) \sum_{m=1}^{\infty} \sum_{n=1}^{\infty}\left(A_{m n} \cos \alpha_{m} x \cos n \theta\right)^{2}\right. \\
& +\frac{2}{R} z\left(\alpha_{m} x\right)^{2}\left(\bar{C}_{12}\right) \sum_{m=1}^{\infty} \sum_{n=1}^{\infty}\left(A_{m n} \cos \alpha_{m} x \cos n \theta\right)^{2} \\
& +\frac{1}{R^{2}}\left(\bar{C}_{22}\right) \sum_{m=1}^{\infty} \sum_{n=1}^{\infty}\left(A_{m n}\left(1-\cos \alpha_{m} x\right) \cos n \theta\right)^{2} \\
& +z^{2} n^{4}\left(\bar{C}_{22}\right) \sum_{m=1}^{\infty} \sum_{n=1}^{\infty}\left(A_{m n}\left(1-\cos \alpha_{m} x\right) \cos n \theta\right)^{2} \\
& +\frac{1}{4}\left(n \alpha_{m} x\right)^{2}\left(\bar{C}_{66}\right) \sum_{m=1}^{\infty} \sum_{n=1}^{\infty}\left(A_{m n} \sin \alpha_{m} x \sin n \theta\right)^{2} \\
& +2 \bar{C}_{12} z^{2}\left(n \alpha_{m} x\right)^{2} \sum_{m=1}^{\infty} \sum_{n=1}^{\infty}\left(A_{m n} \cos \alpha_{m} x \sin n \theta\right)^{2} \\
& \left.-\frac{2}{R} \bar{C}_{22} z n^{4} \sum_{m=1}^{\infty} \sum_{n=1}^{\infty}\left(A_{m n}\left(1-\cos \alpha_{m} x\right) \cos n \theta\right)^{2}\right\} R d z d \theta d x \\
& -\int_{0}^{2 \pi} \int_{0}^{L} N_{x}\left(\alpha_{m} x\right)^{4}\left[\frac{1}{2} \sum_{m=1}^{\infty} \sum_{n=1}^{\infty}\left(A_{m n} \cos \alpha_{m} x \cos n \theta\right)^{2}\right] R d \theta d x
\end{aligned}
$$


The buckling load $N_{c r}$ for clamped boundary condition is obtained by solving the derivative of Eq. (22) with respect to $A_{m n}$ as follows:

$$
\begin{aligned}
& N_{c r}=\left(\frac{2}{\pi L \alpha_{m}^{4}}\right)\left\{\left((R+h)^{3}-R^{3}\right)\left(\alpha_{m}\right)^{4}\left(\frac{\pi L}{2}\right)\left(\bar{C}_{11}\right)+\left(\frac{(R+h)^{2}-R^{2}}{R}\right)\left(\alpha_{m}\right)^{2}\left(\frac{\pi L}{2}\right)\left(\bar{C}_{12}\right)\right. \\
& +\frac{1}{2}\left(\frac{(R+h)^{2}-R^{2}}{R}\right) \bar{C}_{22} n^{5}+\frac{h}{R^{2}}\left(\frac{\pi L}{2}\right)\left(\bar{C}_{22}\right)+\frac{1}{3}\left((R+h)^{3}-R^{3}\right) n^{4}\left(\frac{\pi L}{2}\right)\left(\bar{C}_{22}\right) \\
& +\frac{h}{4}\left(n \alpha_{m}\right)^{2}\left(\frac{\pi L}{2}\right)\left(\bar{C}_{66}\right)+\frac{h}{R^{2}}\left(\bar{C}_{22}\right) \frac{n}{2}+\frac{1}{6}\left((R+h)^{3}-R^{3}\right)\left(\bar{C}_{22}\right) n^{5} \\
& \left.+\frac{2}{3}\left(\frac{\pi L}{2}\right) \bar{C}_{12}\left((R+h)^{3}-R^{3}\right)\left(n \alpha_{m}\right)^{2}-\frac{1}{R} \bar{C}_{22}\left(\frac{\pi L}{2}\right)\left((R+h)^{2}-R^{2}\right) n^{4}\right\}
\end{aligned}
$$

\subsection{The effect of agglomeration}

It has been observed in carbon nanotube reinforced composites that a large amount of the nanotubes are concentrated in agglomerates. The agglomeration is due to their low bending stiffness, so the CNTs can easily agglomerate in the polymer matrix. In fact, there are some local regions in the composite which have higher concentration of CNTs than the average volume fraction. These regions, which have spherical shapes, are called "inclusion". A two-parameter micromechanics model of agglomeration is used to determine the effect of nanotube agglomeration on the elastic properties of randomly oriented CNTs reinforced composites. The regions with concentrated nanotubes are assumed to be spherical in shape with different elastic properties from the surrounding material. The total volume $V_{r}$ of the nanotubes in the representative volume element $V$ can be divided into the following two parts [28]:

$$
V_{r}=V_{r}^{\text {inclusion }}+V_{r}^{m}
$$

where $V_{r}^{\text {inclusion }}$ and $V_{r}^{m}$ denote the volumes of nanotubes dispersed in the inclusions and in the matrix, respectively. The two parameters used to describe the agglomeration are defined as:

$$
\xi=\frac{V_{\text {inclusion }}}{V} \quad, \quad \zeta=\frac{V_{r}^{\text {inclusion }}}{V_{r}}
$$

where $\xi$ denotes the volume fraction of inclusions, with respect to total volume of the composite, and $\zeta$ denotes the volume fraction of nanotubes in the inclusions with respect to the total volume of nanotubes. When $\xi=1$, the nanotubes are uniformly dispersed in the matrix, and with the decrease in $\xi$, the agglomeration degree increases. When $\zeta=1$, all the nanotubes 
are concentrated in the inclusions, and the concentration of nanotubes in the inclusions is decreasing with decreasing $\zeta$. When $\xi=\zeta$, the nanotubes are uniformly distributed within the matrix and $\zeta$ must be greater than $\xi$ for agglomeration to be present. The random dispersion of CNTs renders the composite isotropic with two effective elastic modulus, namely the effective bulk modulus and effective shear modulus [23]:

$$
k=k_{\text {out }}\left[1+\frac{\xi\left(\frac{k_{\text {in }}}{k_{\text {out }}}-1\right)}{\left.1+\alpha(1-\xi)\left(\frac{k_{\text {in }}}{k_{\text {out }}}-1\right)\right)}\right], \quad G=G_{\text {out }}\left[1+\frac{\xi\left(\frac{G_{\text {in }}}{G_{\text {out }}}-1\right)}{1+\beta(1-\xi)\left(\frac{G_{\text {in }}}{G_{\text {out }}}-1\right)}\right]
$$

The effective bulk modulus $k_{\text {in }}, k_{\text {out }}$ and the effective shear modulus $G_{\text {in }}$ and $G_{\text {out }}$, respectively, in the inclusions and out of the inclusions are given by:

$$
\begin{aligned}
& k_{\text {in }}=k_{m}+\frac{\left(\delta_{r}-3 k_{m} \alpha_{r}\right) c_{r} \zeta}{3\left(\xi-c_{r} \zeta+c_{r} \zeta \alpha_{r}\right)}, \quad k_{\text {out }}=k_{m}+\frac{c_{r}\left(\delta_{r}-3 k_{m} \alpha_{r}\right)(1-\zeta)}{3\left[1-\xi-c_{r}(1-\zeta)+c_{r}(1-\zeta) \alpha_{r}\right]} \\
& G_{\text {in }}=G_{m}+\frac{c_{r} \zeta\left(\eta_{r}-2 G_{m} \beta_{r}\right)}{2\left(\xi-c_{r} \zeta+c_{r} \zeta \beta_{r}\right)}, \quad G_{\text {out }}=G_{m}+\frac{c_{r}(1-\zeta)\left(\eta_{r}-2 G_{m} \beta_{r}\right)}{2\left[1-\zeta-c_{r}(1-\zeta)+c_{r}(1-\zeta) \beta_{r}\right]}
\end{aligned}
$$

where $\alpha, \beta, \delta_{r}, \alpha_{r}, \beta_{r}$ and $\eta_{r}$ which are functions of the effective bulk and shear modulus, presented in Ref. [23].

\section{Results and discussion}

In this work, buckling of the composite cylindrical shell reinforced by carbon nanotubes is studied using Rayleigh-Ritz method. The results are given for two different kinds of boundary conditions (C-C \& S-S) and the effects of changing the edge supports are investigated. The cylindrical shell is composed of polystyrene which has demonstrated good dispersion and a strong interfacial bond with nanotubes in experimental works [28]. The Young's modulus and Poisson's ratio of the matrix are $E_{m}=1.9 \mathrm{GPa}$ and $v_{m}=0.3$, respectively. The CNTs are modeled as long, transversely isotropic fiber based on the analytical result of Popov et al. [24] and the material properties of SWCNTs (Hill's elastic modulus) are obtained as $k_{r}=30 \mathrm{GPa}$, $l_{r}=10 \mathrm{GPa}, m_{r}=1 \mathrm{GPa}, n_{r}=450 \mathrm{GPa}, p_{r}=1 \mathrm{GPa}$.

The critical axial buckling loads for different boundary conditions, which are determined by minimizing the total potential energy of the cylinder, are shown in Fig. 2. Buckling loads are presented in non-dimensional forms. Non-dimensional buckling loads are calculated by dividing the value of buckling loads by the smallest buckling load in the first mode of buckling $(n=1)$. The effect of CNTs volume fraction on the critical buckling load is shown in Fig. 2 for four different CNTs orientation angle in the first buckling mode. 
It is seen that, by increasing the volume of CNTs in the composite, the buckling load increases and this increasing is more noticeable for greater angles. Also, the increase in orientation angle $\phi$ (when CNTs are in $90^{\circ}$ they are parallel to the axial direction of cylinder and when they have $0^{\circ}$ orientation they are perpendicular to the axial direction) from $0^{\circ}$ up to $90^{\circ}$ leads to a more stable composite cylinder.

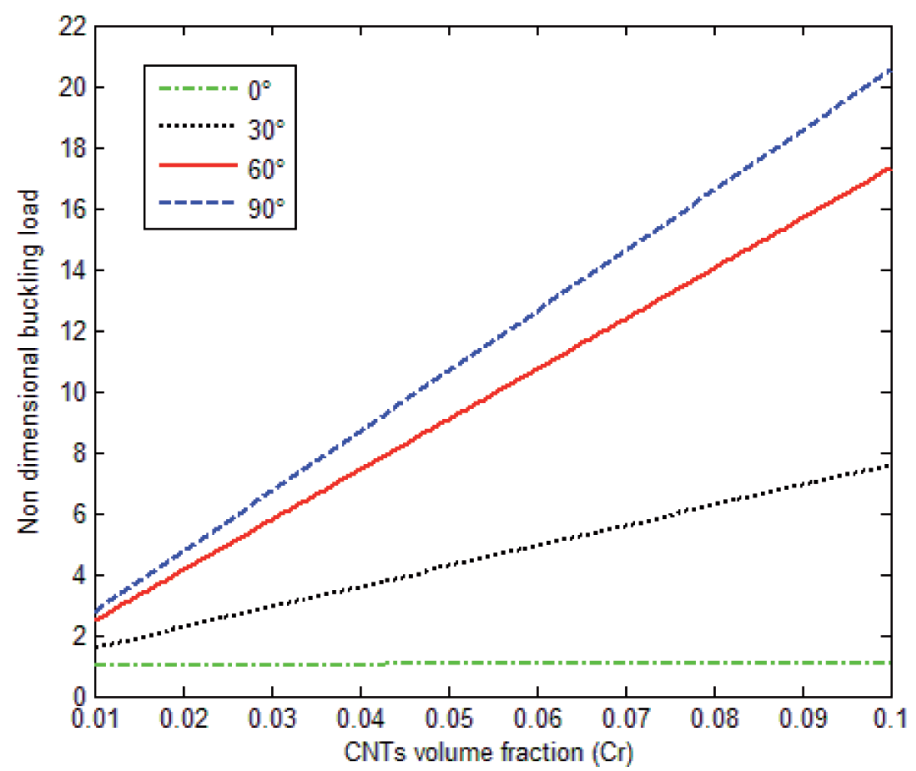

Fig. 2. Effect of the CNTs volume fraction and orientation angle on the critical buckling load. $(\mathrm{h}=2 \mathrm{~mm}, \mathrm{R} / \mathrm{h}=10, \mathrm{~L} / \mathrm{R}=4)$

Figure 3 shows the effect of the orientation angle and CNTs aspect ratio on the critical buckling load of the cylinder. Both sides of the cylindrical shell have simply-supported or clamped boundary conditions. It is seen that by increasing the thickness to length ratio of the cylinder, the cylindrical shell becomes more stable. Also, it is obvious that the highest critical load occurs when the CNTs are arranged in $90^{\circ}$ direction. With the same CNTs, orientation angle and thickness to length ratio, the cylindrical shells with C-C boundary conditions have greater buckling load than S-S supported ones.

The value of critical buckling load that identifies the effect of boundary condition is presented in Table 1 for different thickness to length ratios and orientation angles with $C_{r}=0.1$. As mentioned before, the critical buckling loads are maximal when the CNTs are arranged in $90^{\circ}$ direction. Also it is shown that thicker cylinders have greater buckling load than other ones in the same condition.

The effect of CNTs volume fraction on the buckling of the composite cylinder reinforced by CNTs is demonstrated in Fig. 4(a) and (b) for differ- 


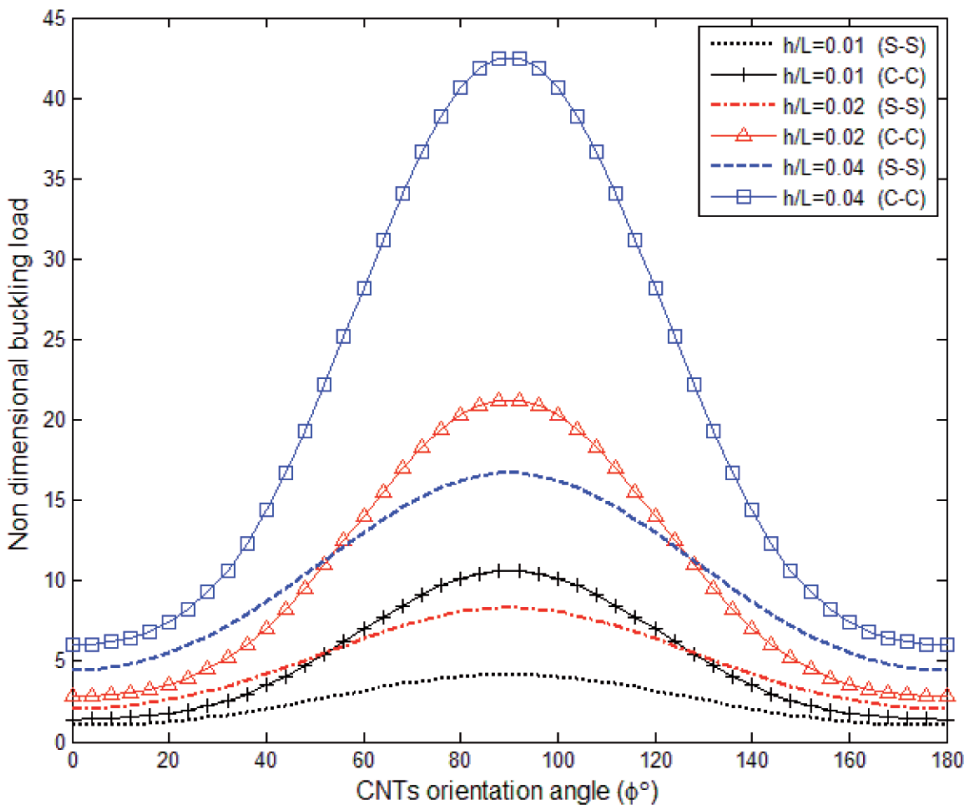

Fig. 3. Effect of CNTs orientation angle and thickness to length ratio on the critical buckling load for S-S \& C-C boundary conditions. ( $\mathrm{L} / \mathrm{R}=5, \mathrm{~L}=0.2 \mathrm{~m}$ )

Table 1.

Critical buckling loads $(\mathrm{KN})$ for different thickness to length ratios and orientation angles within the $\mathrm{S}-\mathrm{S}$ and $\mathrm{C}-\mathrm{C}$ boundary conditions. $(\mathrm{L}=0.2 \mathrm{~m})$

\begin{tabular}{|c|c|c|c|c|c|c|}
\hline \multirow{2}{*}{ B.Cs } & $\begin{array}{c}\text { Thickness to } \\
\text { length ratio }\end{array}$ & $\boldsymbol{\phi}=0^{\circ}$ & $\boldsymbol{\phi}=30^{\circ}$ & $\boldsymbol{\phi}=45^{\circ}$ & $\boldsymbol{\phi}=60^{\circ}$ & $\boldsymbol{\phi}=90^{\circ}$ \\
\hline \multirow{3}{*}{ S-S } & $\mathrm{h} / \mathrm{L}=0.01$ & 234.8 & 378.2 & 549.8 & 749.6 & 977.5 \\
\cline { 2 - 7 } & $\mathrm{h} / \mathrm{L}=0.02$ & 486.1 & 773.1 & 1114 & 1508.5 & 1956.8 \\
\cline { 2 - 7 } & $\mathrm{h} / \mathrm{L}=0.03$ & 754.6 & 1185.3 & 1692.7 & 2277 & 2938 \\
\cline { 2 - 7 } & $\mathrm{h} / \mathrm{L}=0.04$ & 1041.1 & 1615 & 2286.3 & 3054.9 & 3920.9 \\
\hline \multirow{3}{*}{ C-C } & $\mathrm{h} / \mathrm{L}=0.01$ & 327.8 & 558.4 & 996.3 & 1641.7 & 2494.5 \\
\cline { 2 - 7 } & $\mathrm{h} / \mathrm{L}=0.02$ & 672.2 & 1133.5 & 2007 & 3292.9 & 4991 \\
\cline { 2 - 7 } & $\mathrm{h} / \mathrm{L}=0.03$ & 1033.8 & 1725.8 & 3032.5 & 4953.7 & 7489.4 \\
\cline { 2 - 7 } & $\mathrm{h} / \mathrm{L}=0.04$ & 1413.4 & 2335.9 & 4072.8 & 6624.2 & 9990 \\
\hline
\end{tabular}

ent longitudinal and circumferential modes, respectively, with S-S supported boundary conditions. It is obvious that the composite cylinder is more stable if the CNTs volume fraction increases, though it cannot be more than 0.1 because of agglomeration of CNTs in the matrix. Also the buckling load increases for the higher mode numbers as expected. It should be mentioned that the longitudinal mode numbers have greater influence on buckling load 
than circumferential modes. Figure 5(a) and (b) are drawn for four longitudinal modes when the CNTs are arranged in $60^{\circ}$ direction and both ends of the cylinder are simply supported. The buckling load decline in the low cylinder aspect ratios; however, the critical load rises since the aspect ratio increases.

(a)

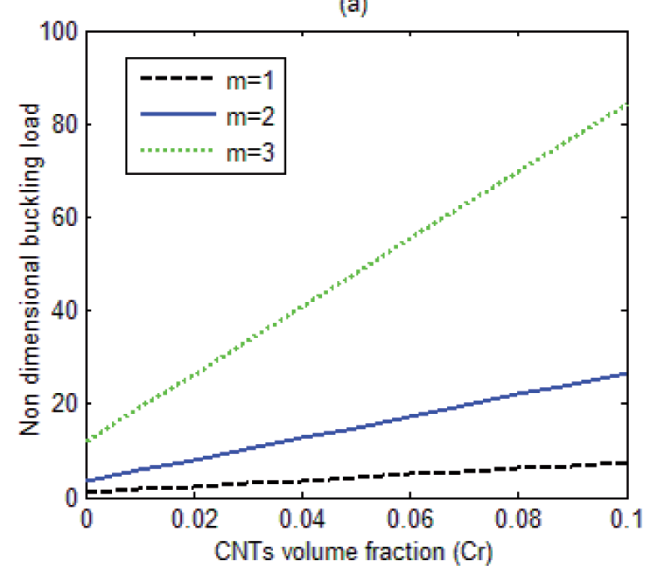

(b)

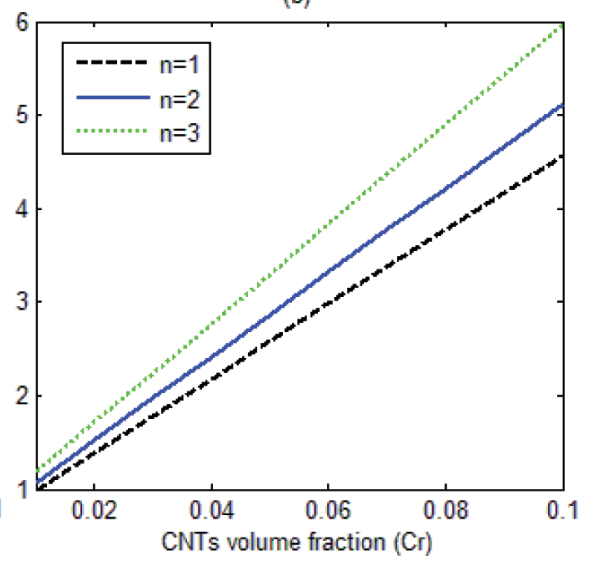

Fig. 4. Effect of CNTs volume fraction on the buckling load for different (a) Longitudinal (b) circumferential mode numbers. $\left(\mathrm{h}=2 \mathrm{~mm}, \mathrm{R} / \mathrm{h}=10, \mathrm{~L} / \mathrm{R}=5, \phi=45^{\circ}\right)$

(a)

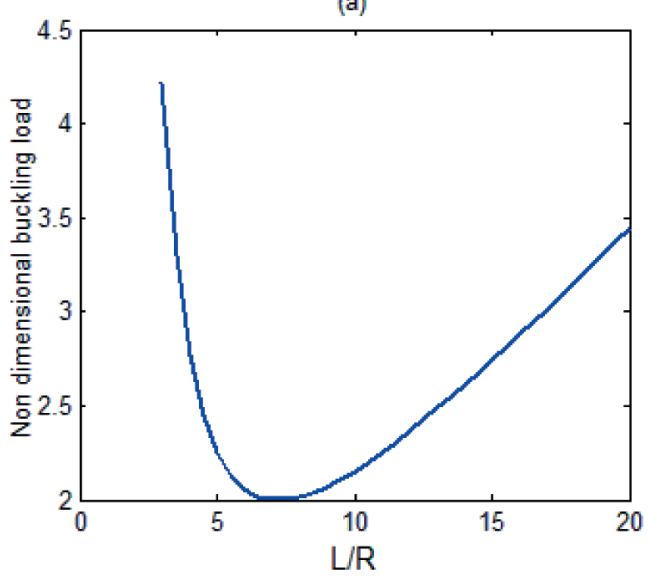

(b)

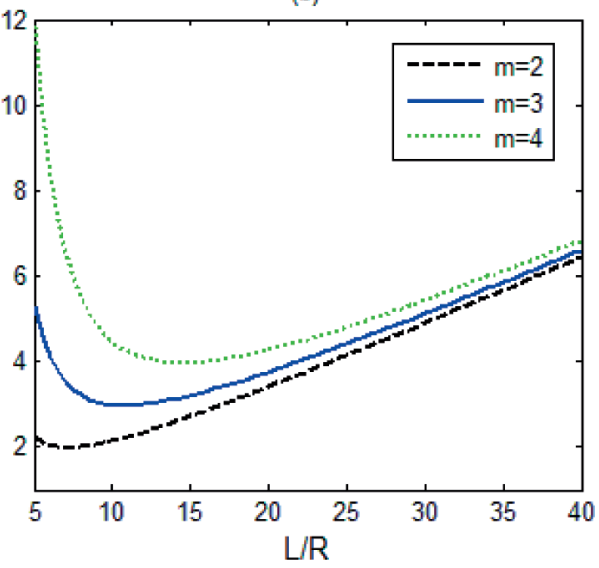

Fig. 5. Effect of length to radius ratio of cylinder on the buckling load for (a) first (b) higher longitudinal mode numbers. $(\mathrm{h}=2 \mathrm{~mm}, \mathrm{R} / \mathrm{h}=10)$

The increase in the buckling load versus the increase in thickness to radius ratio of the cylinder for five circumferential mode numbers is shown in Fig. 6. Figure 7 is related to calculating the non dimensional buckling load for three different CNTs volume fractions when the thickness of the cylinder increased. The results are plotted for both S-S and C-C boundary conditions 
in the first buckling mode. As Fig. 7 shows, increasing of thickness leads to the more stable structure.

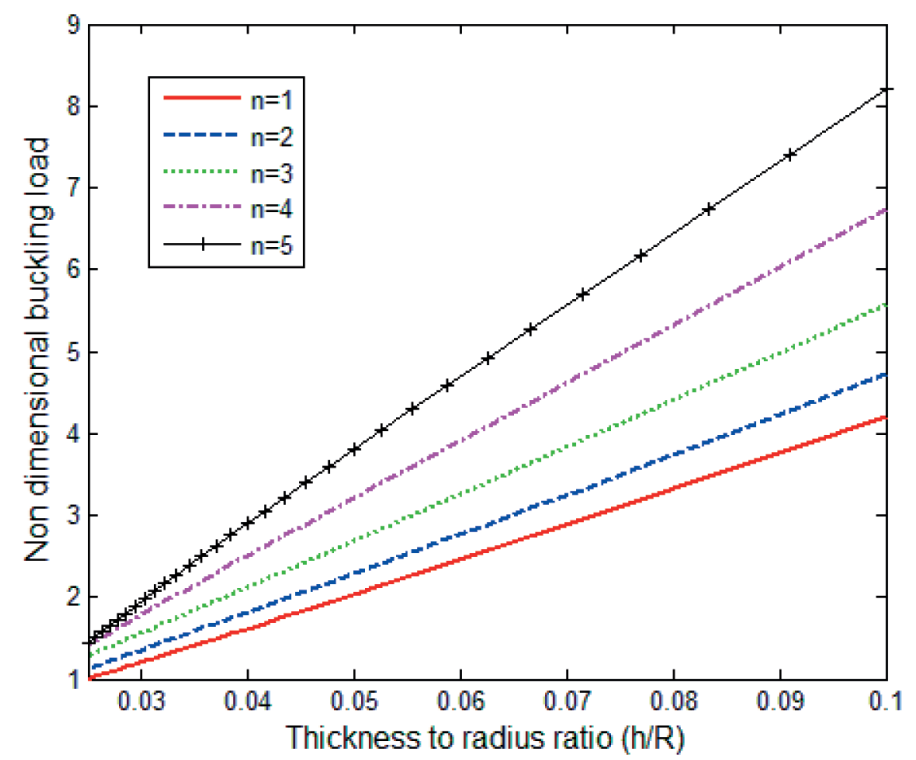

Fig. 6. Variation of buckling load with respect to the ratio of thickness to radius in the different circumferential buckling modes. $\left(\mathrm{m}=1, \mathrm{~h}=2 \mathrm{~mm}, \mathrm{~L} / \mathrm{R}=2, \phi=45^{\circ}\right)$

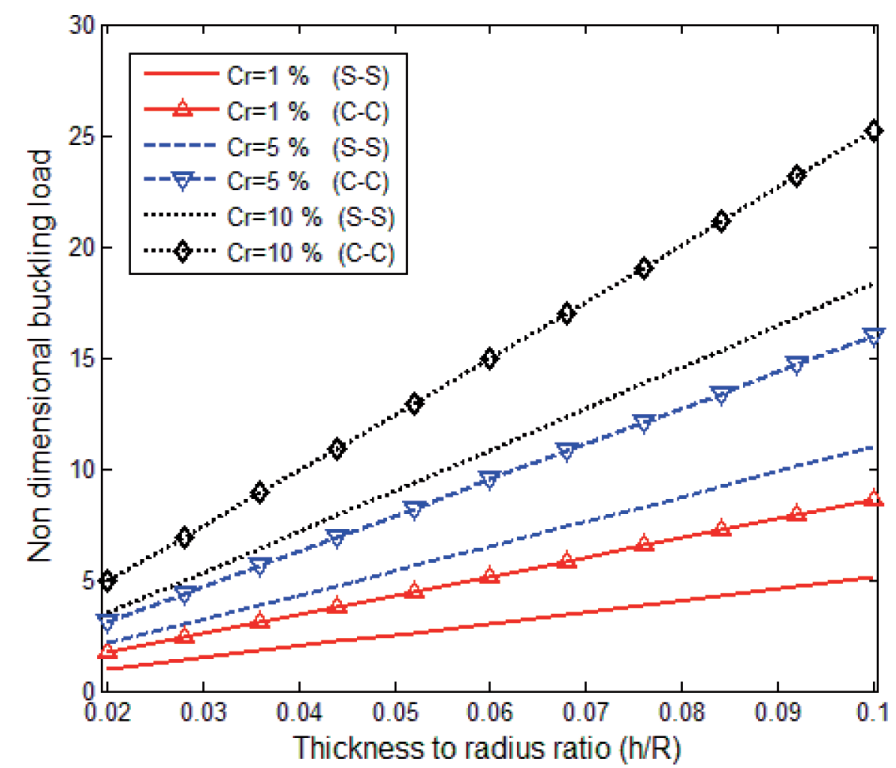

Fig. 7. Effect of thickness to radius ratio and CNTs volume fraction on the buckling load. $\left(\mathrm{L} / \mathrm{R}=5, \phi=30^{\circ}\right)$ 
Figure 8 illustrates variation of buckling load versus length to radius ratio of cylinder in the first five circumferential modes. As shown in this figure, the buckling load decreases in the low ratios and has a minimum value in the specific aspect ratio, and then increases by increasing the length to radius ratio. The effect of longitudinal and circumferential mode numbers is investigated in Fig. 9. The critical buckling load goes up exponentially and the slope of the curves increases sharply in higher longitudinal modes. This figure is also drawn for five circumferential modes and it follows a same pattern for all.

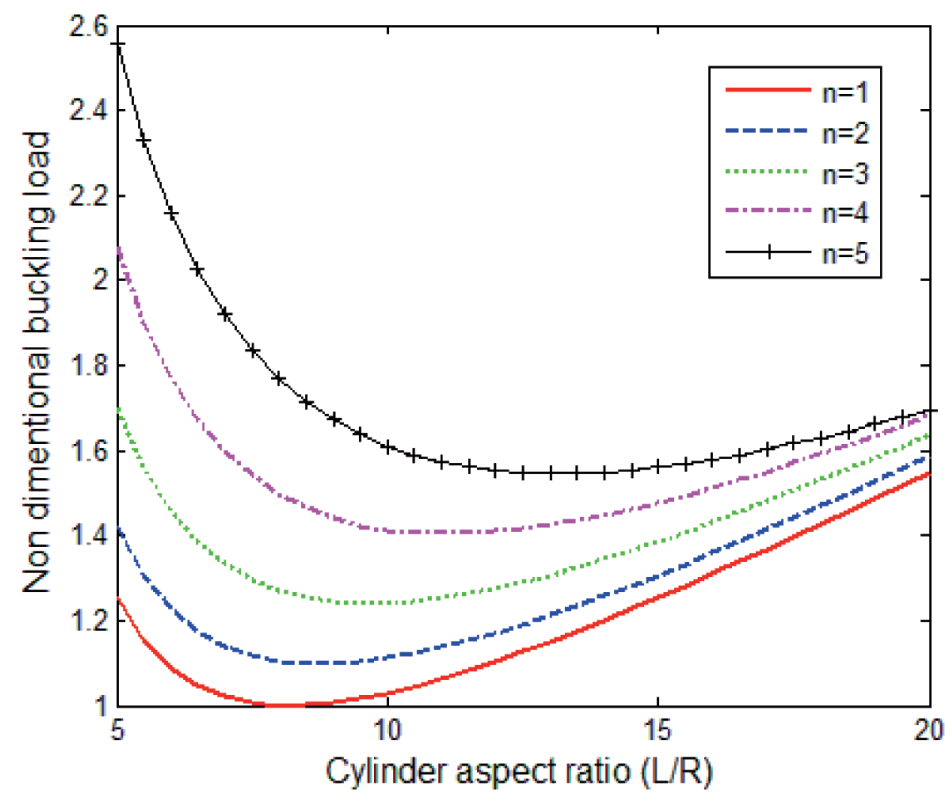

Fig. 8. Minimization of buckling load with respect to the length to radius ratio. ( $\mathrm{h}=2 \mathrm{~mm}$, $\left.\phi=30^{\circ}\right)$

Figures 10 and 11 show the effect of CNTs agglomeration on the buckling load of the cylinder. The CNTs are supposed to arrange randomly. In Fig. 10 , increasing $\xi$ results in a uniform distribution of inclusions. Hence, the nanotubes disperse more uniformly and the critical buckling load increases. The results in this figure are presented for three different volume fractions of CNTs, two boundary conditions and $\zeta=1$ supposed. Increasing $\zeta$ in Fig. 11 leads to a non-uniform dispersion of the CNTs, so the critical buckling load decreases as the $\zeta$ increases. Also it is visible that the critical buckling load is higher for the composites with higher volume fraction of CNTs.

The related values of Fig. 11 are brought into Table 2. According to the values of Table 2, the plate is in the most stable state in the result of minimum agglomeration of CNTs in the matrix. The first column of Table 2 


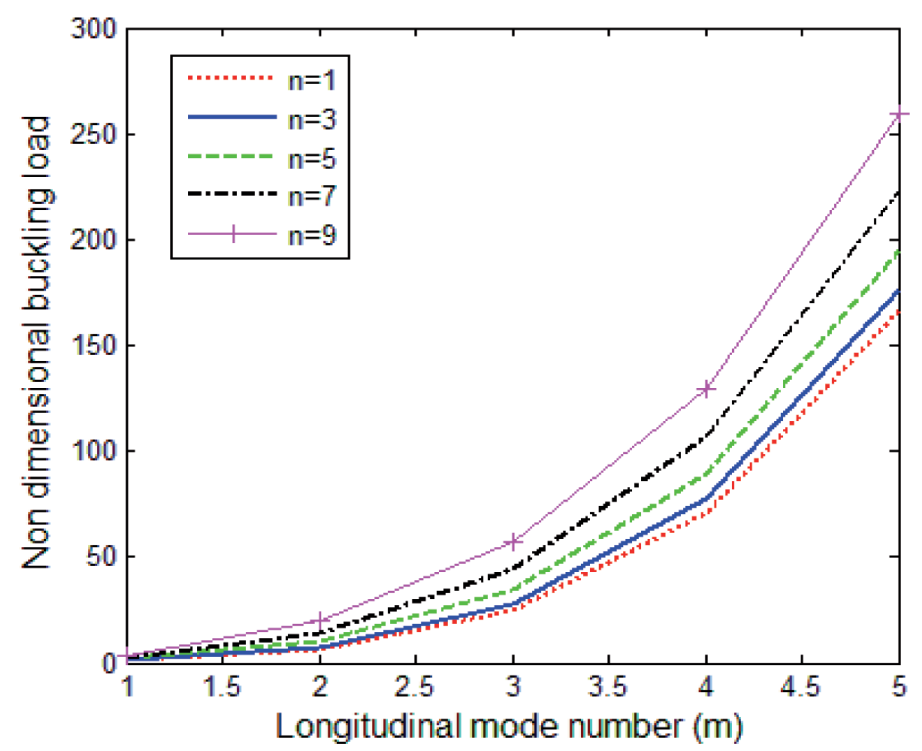

Fig. 9. Buckling loads in the different longitudinal and circumferential mode numbers. $(\mathrm{h}=2 \mathrm{~mm}$, $\mathrm{R} / \mathrm{h}=10, \mathrm{~L} / \mathrm{R}=5, \phi=30^{\circ}$ )

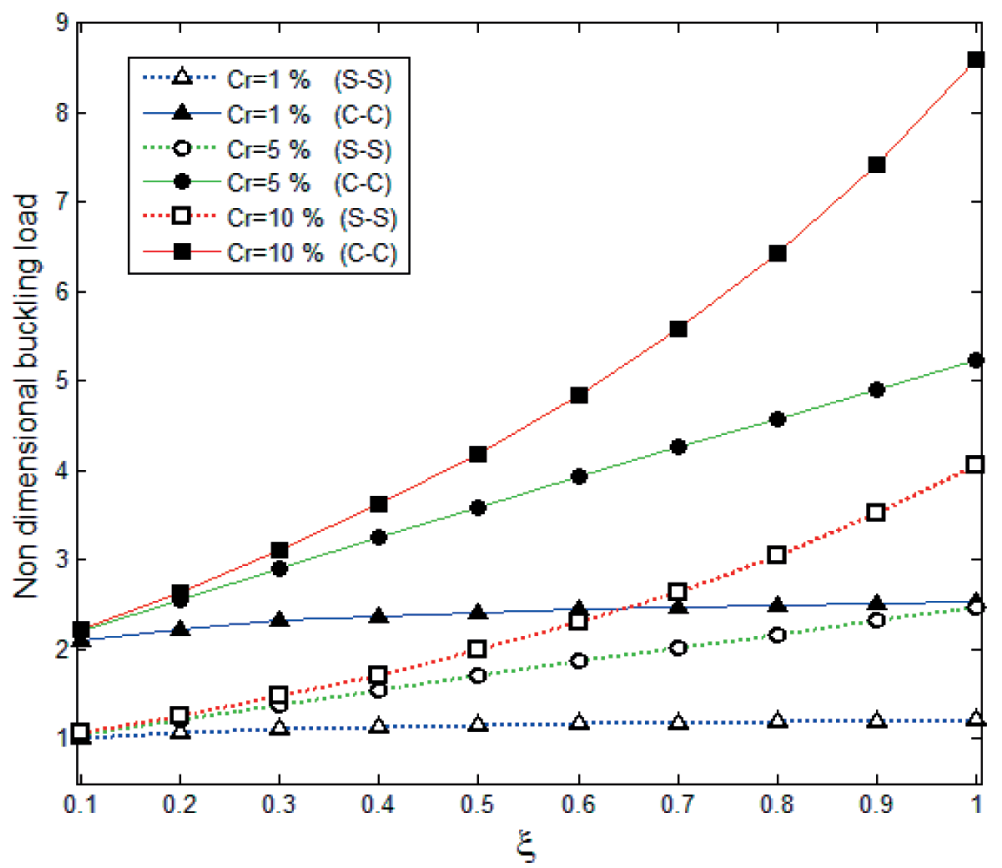

Fig. 10. Effect of the CNTs dispersion in inclusions and CNTs volume fraction on the critical buckling load. ( $\mathrm{h}=2 \mathrm{~mm}, \mathrm{R} / \mathrm{h}=20, \mathrm{~L} / \mathrm{R}=5$ )

shows the type of boundary condition. The CNTs volume fraction for each case of study is presented in the next column. Agglomeration parameters of 


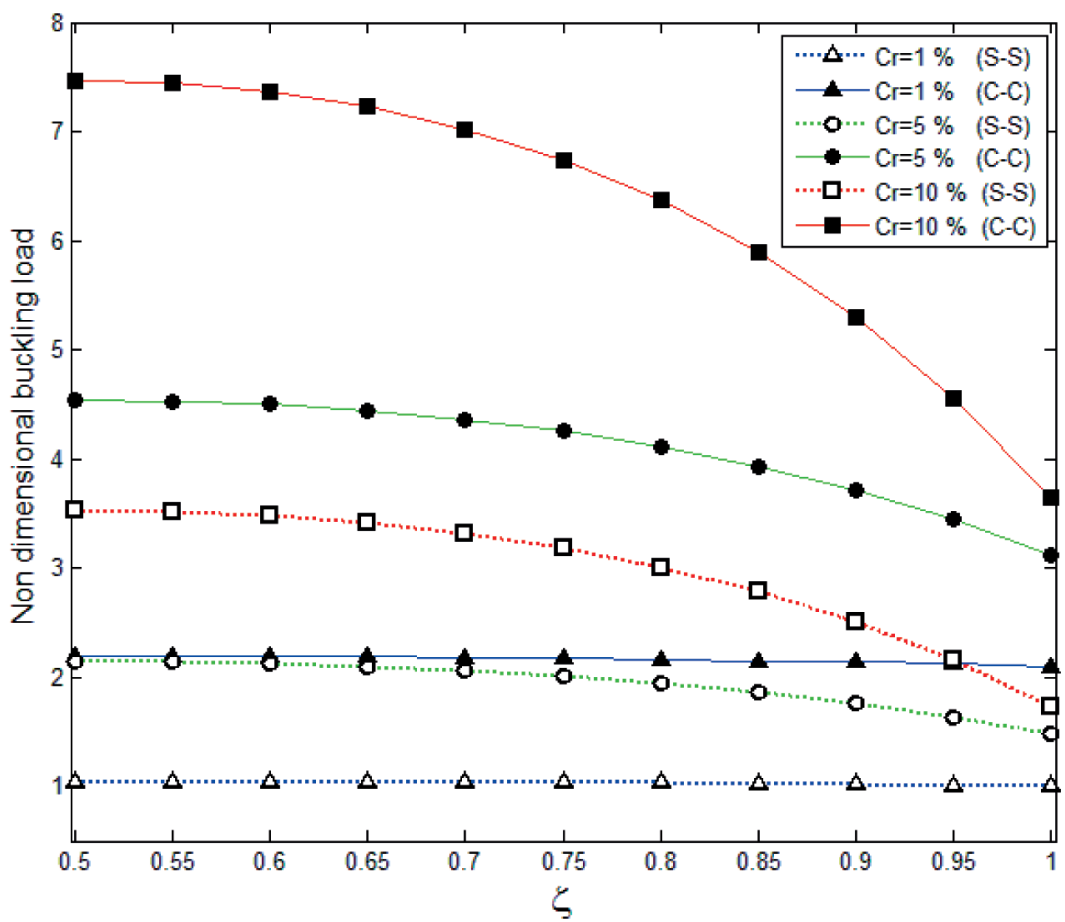

Fig. 11. Effect of the CNTs agglomeration on the critical buckling load for three different volume fractions of CNTs. $(\xi=0.5, \mathrm{~h}=2 \mathrm{~mm}, \mathrm{R} / \mathrm{h}=20, \mathrm{~L} / \mathrm{R}=5)$

0.5, 0.7, 0.9 and 1 are used in this study. It is clearly stems from the results that the critical axial buckling load decreases with increasing the volume of CNTs in the inclusions. Therefore, the highest buckling load occurs at $\zeta=0.5$ for each boundary condition and volume fraction of CNTs.

Table 2

The effect of agglomeration parameter on the buckling load (KN) for different CNTs volume fraction with simply-simply and clamped-clamped boundary conditions.

$$
(\xi=0.5, \mathrm{~h}=2 \mathrm{~mm}, \mathrm{~L}=0.2 \mathrm{~m})
$$

\begin{tabular}{|c|c|c|c|c|c|}
\hline B.Cs & CNTs volume fraction & $\zeta=0.5$ & $\zeta=0.7$ & $\zeta=0.9$ & $\zeta=1$ \\
\hline \multirow{4}{*}{ S-S } & $\mathrm{C}_{r}=1 \%$ & 87.3 & 86.8 & 85 & 83.6 \\
\cline { 2 - 6 } & $\mathrm{C}_{r}=4 \%$ & 156.6 & 151.5 & 133.2 & 117 \\
\cline { 2 - 6 } & $\mathrm{C}_{r}=7 \%$ & 225.7 & 214.6 & 172.9 & 134.1 \\
\cline { 2 - 6 } & $\mathrm{C}_{r}=10 \%$ & 295.2 & 277.5 & 209.4 & 144.5 \\
\hline \multirow{3}{*}{ C-C } & $\mathrm{C}_{r}=1 \%$ & 183.5 & 182.4 & 178.6 & 175.6 \\
\cline { 2 - 6 } & $\mathrm{C}_{r}=4 \%$ & 330.8 & 320 & 281.1 & 246.4 \\
\cline { 2 - 6 } & $\mathrm{C}_{r}=7 \%$ & 477.5 & 454.1 & 365.4 & 282.6 \\
\cline { 2 - 6 } & $\mathrm{C}_{r}=10 \%$ & 624.4 & 587.2 & 442.9 & 304.6 \\
\hline
\end{tabular}




\section{Conclusions}

In this paper, we have presented the buckling of composite cylindrical shells under axial compressive loads reinforced by carbon nanotubes. It is determined that for all the boundary conditions considered, the orientation angle of $90^{\circ}$ yields the highest critical buckling load. The highest critical buckling load occurs for the case in which both inner ends of the cylinder have clamped supports (C-C), while the aspect ratio and CNTs volume fraction are constant. It is observed that the longitudinal mode numbers have a greater influence on buckling load than circumferential modes, and that buckling load increases for the higher mode numbers, as expected. In each longitudinal or circumferential mode number there is a specific value for aspect ratio of the cylinder that minimizes buckling load. Also increasing of cylinder thickness leads to a more stable structure.

The analysis for the effect of CNTs agglomeration shows that critical buckling load decreases as a result of non uniform dispersion of CNTs (decreasing $\xi$ ) in the polymer matrix. However, for very low CNTs volume fractions, uniform dispersion has no important effect on the critical buckling load. Also when the volume fraction of inclusions increases, the critical buckling load decreases exponentially, and buckling load is higher as the volume fraction of CNTs is higher.

Manuscript received by Editorial Board, April 24, 2012;

final version, November 02, 2012.

\section{REFERENCES}

[1] Esawi A.M.K., Farag M.M.: Carbon nanotube reinforced composites - Potential and current challenges. Materials and Design, 2007, Vol. 28, pp. 2394-2401.

[2] Qian D., Wagner G.J., Liu W.K., Yu M.F., Ruoff R.S.: Mechanics of Carbon Nanotubes. Applied Mechanics Reviews, 2002, Vol. 55, pp. 495-533.

[3] Kalamkarov A.L., Georgiades A.V., Rokkam S.K., Veedu V.P., Ghasemi-Nejhad M.N.: Analytical and numerical techniques to predict carbon nanotubes properties. International Journal of Solids and Structures, 2006, Vol. 43, pp. 6832-6854.

[4] Saether E., Frankland S.J.V., Pipes R.B.: Transverse mechanical properties of single-walled carbon nanotube crystals - Part I: determination of elastic moduli. Composites Science and Technology, 2003, Vol. 63, pp. 1543-1550.

[5] Salehi-Khojin A., Jalili N.: A comprehensive model for load transfer in nanotube reinforced piezoelectric polymeric composites subjected to electro-thermo-mechanical loadings. International Journal of Composites, 2008, Vol. 39, Part B, pp. 986-998.

[6] Giannopoulos G.I., Georgantzinos S.K., Anifantis N.K.: A semi-continuum finite element approach to evaluate the Young's modulus of single-walled carbon nanotube reinforced composites. International Journal of Composites, 2010, Vol. 41, Part B, pp. 594-601.

[7] Davis D.C., Wilkerson J.W., Zhu J., Hadjiev V.G.: A strategy for improving mechanical properties of a fiber reinforced epoxy composite using functionalized carbon nanotubes. Composites Science and Technology, 2011, Vol. 71, pp. 1089-1097. 
[8] Maghamikia Sh., Jam J.E.: The Effect of Interfacial Bonding on the Elastic Property of Carbon Nanotube-Reinforced Composite. POLYMER COMPOSITES, 2011, Vol. 32, pp. 1734-1740.

[9] Shao L.H., Luo R.Y., Bai S.L., Wang J.: Prediction of effective moduli of carbon nanotubereinforced composites with waviness and debonding. Composite Structures, 2009, Vol. 87, pp. 274-281.

[10] Hilburger M.W., Starnes J.H.J.: Buckling behavior of compression-loaded composite cylindrical shells with reinforced cutouts. International Journal of Non-Linear Mechanics, 2005, Vol. 40, Issue 7, pp. 1005-1021.

[11] Dong L., Mistry J.: An experimental study of the failure of composite cylinders subjected to combined external pressure and axial compression. Composire Strucfures, 1998, Vol. 40, No. 1. pp. 81-94.

[12] Meyer-Piening H.-R., Farshad M., Geier B., Zimmermann R.: Buckling loads of CFRP composite cylinders under combined axial and torsion loading- experiments and computations. Composite Structures, 2001, Vol. 53, pp. 427-435.

[13] Elghazouli A.Y., Chryssanthopoulos M.K., Spagnoli A.: Experimental response of glassreinforced plastic cylinders under axial compression. Marine Structures, 1998, Vol. 11, pp. 347-371.

[14] Spagnoli A., Elghazouli A.Y., Chryssanthopoulos M.K.: Numerical simulation of glassreinforced plastic cylinders under axial compression. Marine Structures, 2001, Vol. 14, pp. 353-347.

[15] Topal U.: Multiobjective optimization of laminated composite cylindrical shells for maximum frequency and buckling load. Materials \& Design, 2009, Vol. 30, Issue 7, pp. 2584-2594.

[16] Chryssanthopoulos M.K., Elghazouli A.Y., Esong I.E.: Validation of FE models for buckling analysis of woven GFRP shells. Composite Structures, 2000, Vol. 49, pp. 355-367.

[17] Jam J.E., Maghamikia Sh.: Elastic buckling of composite plate reinforced with carbon nanotubes. International Journal of Engineering Science and Technology, 2011, Vol. 3, pp. 40904101.

[18] Maghamikia Sh., Jam J.E.: Buckling analysis of circular and annular composite plates reinforced with carbon nanotubes using FEM. Journal of Mechanical Science and Technology, 2011, Vol. 25, pp. 2805-10.

[19] Jam J.E., Kia S.M., Pour A.G., Emdadi M.: Elastic Buckling of Circular Annular Plate Reinforced With Carbon Nanotubes. Polymer Composites, 2011, doi: 10.1002/pc.21103.

[20] Matsunaga H.: Vibration and buckling of cross-ply laminated composite circular cylindrical shells according to a global higher-order theory. International Journal of Mechanical Sciences, Vol. 49, Issue 9, pp. 1060-1075.

[21] Tan H., Huang Y., Liu C., Geubelle P.H.: The Mori-Tanaka method for composite materials with nonlinear interface debonding. International Journal of Plasticity, 2005, Vol. 21, Issue 10, pp. 1890-1918.

[22] Kollar L.P., Springer G.S.: Mechanics of composite structures. New York, Cambridge University Press, 2003.

[23] Shi D.L., Feng X.Q., Huang Y.Y., Hwang K.C., Gao H.: The effect of nanotube waviness and agglomeration on the elastic property of carbon nanotube reinforced composites. Journal of Engineering Materials and Technology, 2004, Vol. 126, No. 3, pp. 250-258.

[24] Popov V.N., Dorena V.E., Balkanskib M.: Elastic properties of crystals of single-walled carbon nanotubes. Solid State Communications., 2000, Vol. 114, pp. 395-399.

[25] Vinson J.R.: The Behavior of Thin Walled Structures, Beams, Plates and Shells, Netherlands, Kluwer Academic, 1989.

[26] Simitses G.J.: An introduction to elastic Stability of Structures. New York, Prentice - Hall, 1976.

[27] Reddy J.N.: Theory and analysis of elastic plate and shells, Second edition, USA, CRC PRESS (Taylor and Francis), 2007. 
[28] Wuite J., Adali S.: Deflection and stress behaviour of nanocomposite reinforced beams using a multiscale analysis. Composite Structures, 2005, Vol. 71, pp. 388-396.

\section{Analiza wyboczenia cylindrycznych powłok kompozytowych wzmocnionych nanorurkami węglowymi}

\section{Streszczenie}

W artykule przedstawiono badania powłoki cylindrycznej wzmocnionej nanorurkami węglowymi (Carbon Nanotubes - CNT). Krytyczne obciążenie wyboczenia obliczono analitycznie dla przypadku osiowego obciążenia ściskającego. Metodę Mori-Tanaki wykorzystano przede wszystkim w celu estymacji efektywnego modułu sprężystości kompozytów wzmocnionych prostymi rurkami CNT o orientacji równoległej. Wartości własne problemu wyznaczono stosując podejście analityczne oparte na zoptymalizowanej metodzie Rayleigha-Ritza. Zaprezentowano studium dotyczące wpływu udziału objętościowego nanorurek CNT, grubości i współczynnika kształtu powłoki, kąta orientacji nanorurek CNT i typu podparcia powłoki cylindrycznej przy obciążeniu krytycznym przy wyboczeniu. Ponadto, zbadano efekt aglomeracji nanorurek CNT dla przypadku, gdy rurki są nierównomiernie rozproszone $\mathrm{w}$ osnowie polimerowej. Pokazano, że gdy nanorurki są ustawione pod kątem 90? obciążenie krytyczne wyboczenia jest największe. Ponadto, przedstawiono wykresy wyników dla różnych liczb modów osiowych i obwodowych. Istnieje określona wartość współczynnika kształtu, przy której obciążenie wyboczenia jest minimalne. Uzyskane wyniki pokazują, że przy bardzo niskim udziale objętościowym nanorurek CNT procentowa zawartość wtrąceń nie ma istotnego wpływu na obciążenie krytyczne przy wyboczeniu. 